http://www.jfas.info

\title{
WEB-BASED VIRTUAL LEARNING ENVIRONMENT (EMOVILE) WITH EMOTIVE INTERFACE FEATURE
}

\author{
M. Mokhsin ${ }^{1,2, *}$, A. A. Aziz ${ }^{1}$, A. Z. Shahuddin ${ }^{1}$, A. M. Lokman ${ }^{1}$ and M. S. Idris ${ }^{1}$ \\ ${ }^{1}$ Faculty of Computer and Mathematical Sciences, Universiti Teknologi MARA, 40450 Shah \\ Alam, Selangor, Malaysia \\ ${ }^{2}$ Institute of Malay Thought and Leadership, Universiti Teknologi MARA, 40450 Shah Alam, \\ Selangor, Malaysia
}

Published online: 05 October 2017

\begin{abstract}
This study attempts to obtain the user requirements for the EmoViLE during the data collection and to identify the user requirement for the EmoViLE. This VLE will be benefited to the student by improving the user experience and increasing their engagement when using the VLE, and lecturer in helping them to understand their student better and to come out with a better future plan for their learning assessment. The methodology in doing this study are Phase 1 which involved the initial study on the previous work, Phase 2 is the data collection on the user requirement, Phase 3 which involves the design process of the VLE, Phase 4 is the development phase of the VLE and Phase 5 is the testing on the prototype of the VLE. The expected outcome is a prototype of the VLE with the emotive interface feature that can contribute for the improvement and betterment on teaching and learning process between students and lecturer.
\end{abstract}

Keywords: emotions; virtual learning environment; web-based teaching; web-based learning; dashboard; Kansei engineering.

Author Correspondence, e-mail: mudiana@tmsk.uitm.edu.my

doi: http://dx.doi.org/10.4314/jfas.v9i4s.25 


\section{INTRODUCTION}

The evolution of technology and the expanding of internet user have pushed the use of virtual learning environment (VLE) in higher education. Emotion in the other hand can change how the student thinks, act and cooperate with other and in learning environment. Even though information about emotion has been seen to give benefits in education, there are less VLE that support the emotive interface feature. Therefore, as the factors have been identified, a virtual learning environment with emotive interface feature can be designed according to the requirements. By integrating emotive aspect to the VLE, it can change and improve the current practice of VLE and bring it step forward from the old one. Furthermore, instructor can has better understanding of their students and can plan better education in the future. Students' engagement also can be improved and motivate them to use the system. Emotion is an important aspect that people often overlook in education. Research on emotions in education has shown that students experience a rich variety of emotions in academic settings [1]. Thus, it is important for emotion to be emphasized in an education. In a virtual learning environment, it is exceptionally valuable to distinguish the condition of mentality of the student in a reasonable and programmed way. Based on the preliminary study of the current i-Learn website, there is none emotional features that has been integrates or implements. Therefore, there is a requirement for change in learning environments and the way those distance learning courses happen [2]. Thus, this project will be focusing on a research on how the emotional design elements can be implemented in the virtual learning environment and how it can be developed.

\section{PROBLEM STATEMENT}

One of the important components of virtual learning is providing appropriate and specific feedback to students [3] (As cited in [4]). User interaction and feedback in online learning material can engage and motivate the student [5]. Moreover, lecturer also can have better understanding of their students. Based on preliminary study of i-Learn system, the only interaction that can be done by student and lecturer is only by creating a course forum. Furthermore, most of them did not even know or use the function. Therefore, to be more 
effective, implementing a comment section and emotional feedback in every course material is recommended.

Based on preliminary study of Faculty of Computer and Mathematical Sciences (FSKM) student in different campus, majority of the student agree that the current i-Learn system has poor user interface which lead to user unsatisfactory. Furthermore, the information architecture such as navigation and organization system is poorly design. Web-based design always results in conflict between the designer's specification and the user's conformance [6]. This can evoke negative emotion to the student which makes them to less likely to use the system again.

\section{LITERATURE REVIEW}

\subsection{Virtual Learning Environment}

In education, internet technology is used to create a new form of education for students which is Virtual Learning Environment (VLE). Virtual learning environment also can be defined as virtual worlds which provide for an abstract form of reality, where learners are not physically present but instead use technology to interact with and objects in the virtual world [7]. Virtual learning is divided into different structures with changing degrees of online interest and in addition different sorts of members [8]. VLE are usually conducted based on the environment of distance education. In distance education, instructors and understudies impart and connect by means of a VLE [2]. It regularly portrays the attempt of giving permission to education for the individuals who live far away [10]. Therefore, VLE can be seen as another medium of learning which provide virtual interaction remotely to user by utilizing the internet and computerized technology.

\subsection{Virtual Learning Environment Functions and Advantages}

One of the virtual learning functions is to provide resources sharing among students and lecturers. Research says that learning sources shared by the internet are multiply swiftly [11]. These learning sources consist of lecture videos, online teaching notes, Internet chat groups, online interactive problem sets with instantaneous feedback or grading, educational games and many other growing technologies. In particular, lesson is distributed by the virtual 
learning using computer program, internet or both [12].

Numerous materials might be traded from understudy to instructor and the other way around; they can choose whether to print it when needed which avoid unnecessary paper misuse [13]. Another source also suggest that with virtual learning, substance can be devoured any place, any time and on any platform [14]. Online systems are recognize as performing to a progressive movement in education through the adaptability of happening anyplace, whenever and at a lesser expense than traditional ways [15]. Furthermore, it can possibly enhance student accomplishment, learning opportunity and institution expenditure efficiency [12].

\subsection{Emotion in Education}

Emotion can be tool or way to describe someone personality or status. Emotions refer to the individual's adaptation to his social environment, being facial, body and verbal expression, the main means of communication of emotional state to others [9]. Thus, the connection between cognition and emotion by involving reflection about the situation that arises allows determining ones' behavior. It also stated that specific tools are needed to identify positive and negative emotion and also behaviors that happen during education. Emotion can be divided into two parts which are positive and negative. The study about the multimedia learning has concluded that both students' emotional condition and emotional design of a learning program had an effect on affective and cognitive processes influencing learning [16]. It also stated that positive mood condition before education course improved the learning outcome and the combination with the design of a learning environment result to the highest learning outcome. "Positive-activating emotions such as enjoyment have been found to positively relate to the use of deep-level cognitive learning strategies" and "negative-deactivating emotions such as boredom," act as encouragement blockade, hinder with students' capability to study in scholarly environments. Furthermore, while boredom had a negative impact on metacognitive learning strategies, frustration influenced the student positively. The study concludes emotional experiences subsequently influenced students' performance, which also affects their level of learning. In addition, each emotion orchestrates a complex suite of changes in motivation, physiology, attention, perception, beliefs and behaviors [17]. Nevertheless, both positive and negative emotions still affect people in certain way whether it is bad or a good 
thing. Thus, it is important to know how this different emotion can affect the virtual learning environment.

\subsection{Emotion in Virtual Learning Environment}

Virtual learning environment (VLE) has become more advance as time passing and changing every time. There is a requirement for change in learning environments and the way those distance learning courses happen [2]. Thus, further research on the VLE in education is needed. User feedback and interaction is one of the factors that can be research to improve the VLE Therefore, feedback and user interaction is one of the main of factor to make VLE more successful. Emotion in virtual learning environment can be considered as user feedback or interaction in virtual learning environment, which is close related to user decision or choice. Individuals regularly isolate emotion and logic, trusting that emotions are a hindrance in making logical choice or thinking [9]. In reality, emotion plays an important role in people life which affects their thinking and decision. In a virtual learning environment, it is exceptionally valuable to distinguish the condition of mentality of the understudy in a reasonable and programmed way [2]. Emotion mindfulness and the capacity to oversee emotions suitably is the premise for successful correspondence and can comprehend and feel for what is disturbing other individuals. An adjustment in the learner's enthusiastic state can orientate their consideration center and can affect an adjustment in the way they think, act and cooperate with others and in addition control their attitude in a learning circumstance [9]. Thus, a student seeing high assignment esteem but low regulation over the learning exercise will not accomplish a high result [7]. In conclusion, emotion highly affects the virtual learning environment by changing the way individual thinking and how they make decision.

\subsection{Existing System (i-Learn)}

I-learn system is used for students in Universiti Teknologi MARA (UiTM). Study has been made and currently the system lacks the function for the students or lecturers to interact with each other. It is because the system only has forum function and does not have chat, comment or any other type of interaction between student and lecturer. Currently, the function of the system is sharing learning material, online quiz, announcement and feedback of the courses. The website only support static and liquid layout which is not suitable for mobile device. The 
system navigation of the website is poorly designed, which make it hard to navigate through the site. The system also does not use many icons and use mostly text which can make it hard to scan with eye. Based on the interview with the Faculty of Computer and Mathematical Sciences (FSKM), UiTM students, the main problem of i-Learn system is mainly on the usability and the user interface design. The system also has poor information architecture which makes some task hard and complex. The achievement of a website is contributed by the quality and the skill of designing the website [18]. Thus, this project will be focusing on the design of the VLE website using emotional design elements. Furthermore, it has been identified that there is lack of user engagement such as communication with others in the current i-Learn system. Communication with others in the environment will move the student from their present education to a possible for better improvement [8]. Therefore, this project will be also focusing on how the communication could be implemented on the system.

\subsection{Emotional Design Factors}

Webpage design has turn into a vital component affecting user satisfaction when they browse the internet [19]. Based on their research about optimization design of a webpage based on Kansei Engineering, nine key design factors and 13 sub factors were determined on job-hunting website homepage. Four key designs have been identified to be potentially useful for these projects which are the body, logo, navigation and login of the website. The first factor which is body of the website refers to the overall visual effect of the whole design which has two factors; "Color" and" Layout style". Next, the design factor of the logo is the "Position" while navigation has three factors which are "Interaction", "Feature" and "Style". All of these factors are crucial to obtain near-optimal designs, which can closely adapt to users' emotional needs.

Building a qualitative and reactive user interface prevails a practical objective of learning system development [20]. Their research suggests that animation allow enhanced learning because they add emotional interactions in addition to improving the appeal of an interface. Recent studies indicated that the emotional design of multimedia learning material can evoke positive emotions in learners that will improve the education process [21]. Their research finding suggest that learner's emotional statuses had a slight influence on learning outcomes, 
but a greater influence on learners' intrinsic motivation including the motivation to stay working with the material. Color alongside with other three core dimension of website visual aesthetics (simplicity, diversity and craftsmanship) appear to be suitable for inducing positive emotions in education. At more detail level, aesthetic color and color combinations can be utilized to evoke positive emotional reactions. However, long loading times in design features is most relevant to inducing negative emotions. In conclusion, four key design need to be focused on this project which are body, logo, navigation and login of the website. Further factors such as layout and colors also need to be considered and emphasize. Moreover, visual aesthetics such as color has been identified to be the factor to evoke positive emotions and long loading times need to be evading in avoiding negative emotions. In addition, animation also can allow enhanced learning and a ways to describe events which cause reaction within a view should be provided.

\section{METHODOLOGY}

\subsection{Data Collection Procedures}

Interview session has been done between the lecturers. Whereby interviewees should be VLE regular users within their departments and should have used the following tools with their classes prior to interviews: forum, test, videos and feedback in the form of semi structured. The purpose is to establish the impact the adoption of VLEs have on students' emotion from lecturer's perspective which inquire about collaboration, self-esteem, relationship management, classroom ambience etc. The focus group of the project will consist of the student of UiTM in FSKM. Five focus groups comprising randomly five to seven students have been selected to be interviewed as follows:

a) Part 2 (1 group)

b) Part 3-4 (2 groups)

c) Part 5-6 (2 groups)

The purpose of this interview is to obtain student's point of view in the current system. All discussions will be held on student preferred location.

\subsection{Development}


Web Development Life Cycle (WDLC) has been used throughout the development of the system. The first phase is project planning and followed by system requirement analysis, system design, implementation, testing, acceptance and deployment and lastly maintenance. However, this project will only focus on the first five phases whereby it has been done until testing phase. Table 1 shows the phases involved in this study.

Table 1. Methodology activities and deliverables in each phases

\begin{tabular}{|c|c|c|}
\hline Phase & Activity/Technique & Deliverable \\
\hline \multirow[t]{3}{*}{$\begin{array}{l}\text { Project } \\
\text { Planning }\end{array}$} & $\begin{array}{l}\text { Identify the problem statements, } \\
\text { objectives, scope, focus elements and } \\
\text { the significance of the project. } \\
\text { (Tools: online journal, article and online } \\
\text { material) }\end{array}$ & $\begin{array}{l}\text { - } \text { Problem statement } \\
\text { - } \text { Objectives } \\
\text { - Scope } \\
\text { - Focus elements } \\
\text { - Significance }\end{array}$ \\
\hline & $\begin{array}{l}\text { - Identify the user requirements } \\
\text { (Techniques: observation and interview) }\end{array}$ & $\begin{array}{l}\text { - List of user's } \\
\text { requirement }\end{array}$ \\
\hline & - Choose the suitable methodology & $\begin{array}{l}\text { Web Development } \\
\text { Life Cycle (WDLC) }\end{array}$ \\
\hline \multirow[t]{2}{*}{$\begin{array}{l}\text { System } \\
\text { Requirement } \\
\text { Analysis }\end{array}$} & $\begin{array}{l}\text { - Identify the functional and } \\
\text { non-functional requirements based on } \\
\text { the similar existing system. } \\
\text { (Techniques: observation) }\end{array}$ & $\begin{array}{l}\text { - A list of functional and } \\
\text { non-functional } \\
\text { requirements. }\end{array}$ \\
\hline & $\begin{array}{l}\text { Identify what hardware and software to } \\
\text { be used in development of web-based } \\
\text { system. }\end{array}$ & $\begin{array}{l}\text { - A list of hardware and } \\
\text { software needed. }\end{array}$ \\
\hline \multirow[t]{2}{*}{$\begin{array}{l}\text { System } \\
\text { Design }\end{array}$} & $\begin{array}{l}\text { - Design the storyboard } \\
\text { (Tool: Balsamiq Mockups 3) }\end{array}$ & - Web site storyboard \\
\hline & - Design the use case diagram & - Use Case diagram \\
\hline
\end{tabular}




\begin{tabular}{|c|c|c|}
\hline & (Tool: StarUML) & \\
\hline & $\begin{array}{l}\text { Design the ERD } \\
\text { (Tool: MySQL Workbench } 6.3 \mathrm{CE} \text { ) }\end{array}$ & - ERD diagram \\
\hline & $\begin{array}{l}\text { Design the DFD } \\
\text { (Tool: Microsoft Visio) }\end{array}$ & - DFD diagram \\
\hline \multirow[t]{2}{*}{ Development } & $\begin{array}{l}\text { Develop the EmoViLE web system } \\
\text { database } \\
\text { (Tool: MySQL Workbench } 6.3 \mathrm{CE} \text { ) }\end{array}$ & - The system database \\
\hline & $\begin{array}{l}\text { Develop the web system } \\
\text { (Tool: Adobe Dreamweaver CC) }\end{array}$ & $\begin{array}{l}\text { - The complete } \\
\text { EmoViLE web system }\end{array}$ \\
\hline Testing & $\begin{array}{l}\text { - Usability testing } \\
\text { (Techniques: Cognitive walkthrough, } \\
\text { Thinking aloud) }\end{array}$ & $\begin{array}{l}\text { Usability result in a } \\
\text { form of feedback and } \\
\text { report }\end{array}$ \\
\hline
\end{tabular}

Fig. 1 until Fig. 14 are the screenshots of the prototype for further understanding of the EmoviLE:

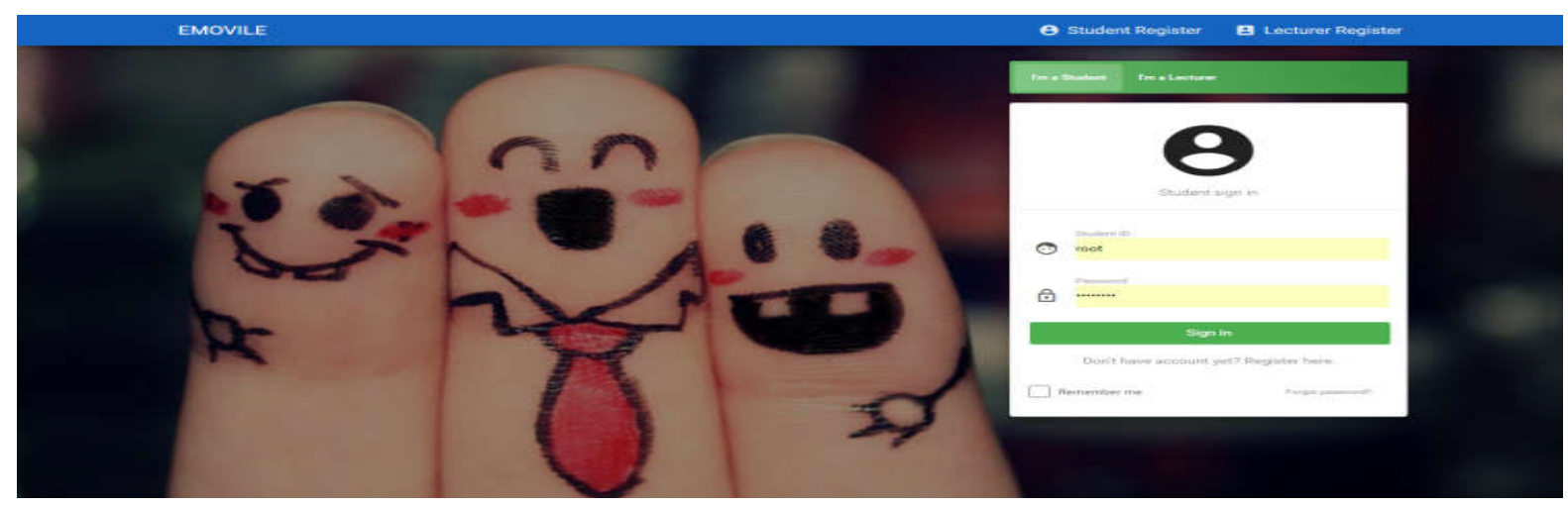

Fig.1. Login page screenshot

The purpose of having login system is to enable only the valid user to enter the system which is the student and the lecturer. User account information was stored in the database to have it secure from hacker. Once login, student and staff will go to different page intended to them 


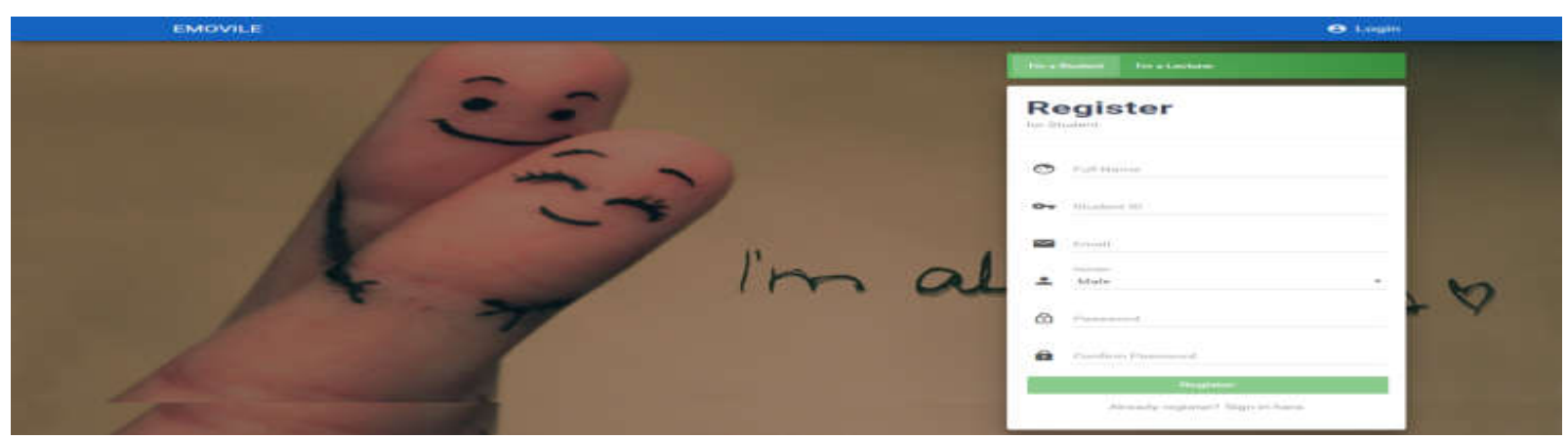

Fig.2. Register page screenshot

Before student or lectures are allowed to access the system, they need to register as a user for the first time. User need to click register button either for student or lecturer. At the registration page, all inputs are needed to be filling in.

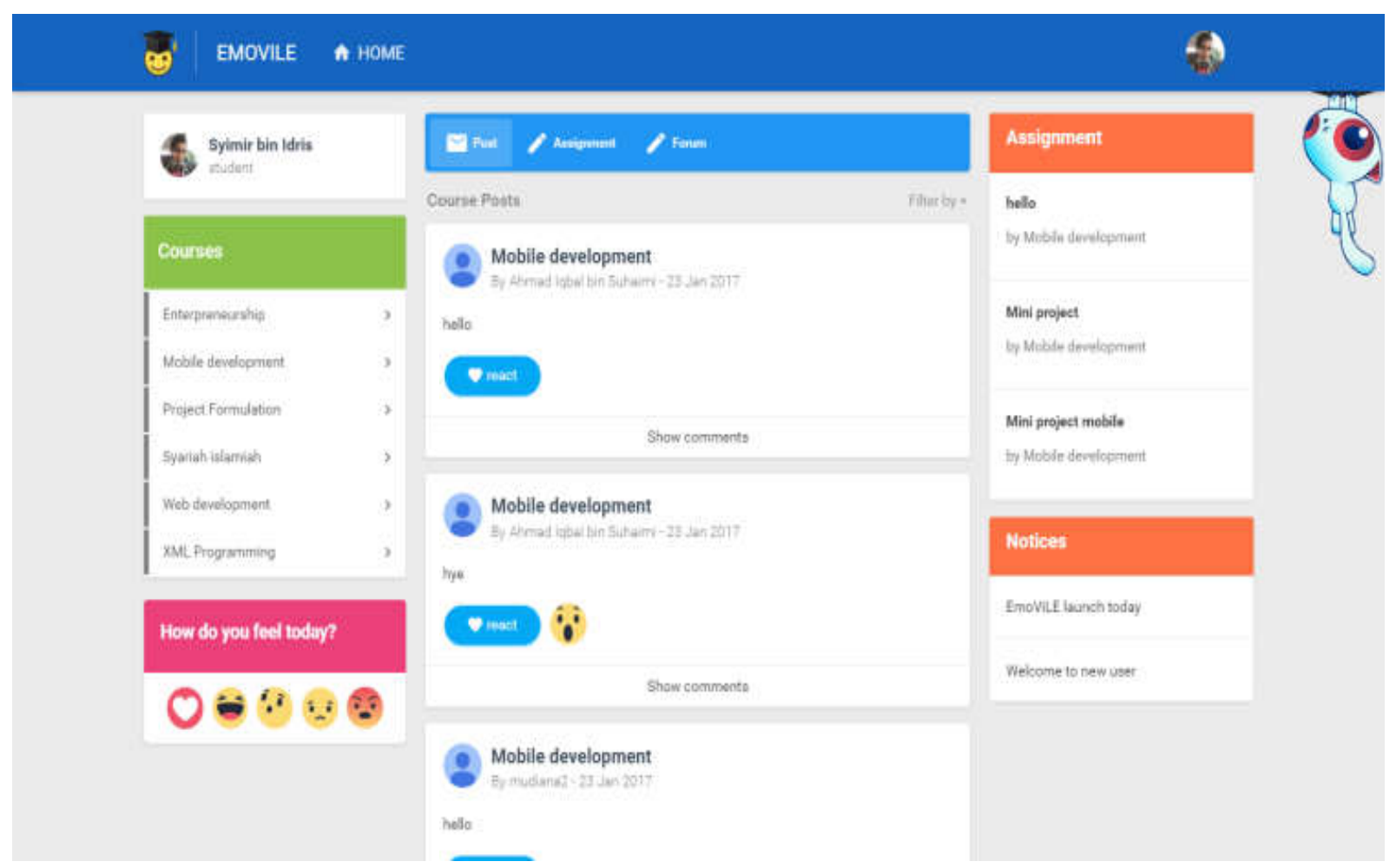

Fig.3. Student main page screenshot

After successful login as student, they will be redirect to student home page as shown in Fig. 3. 


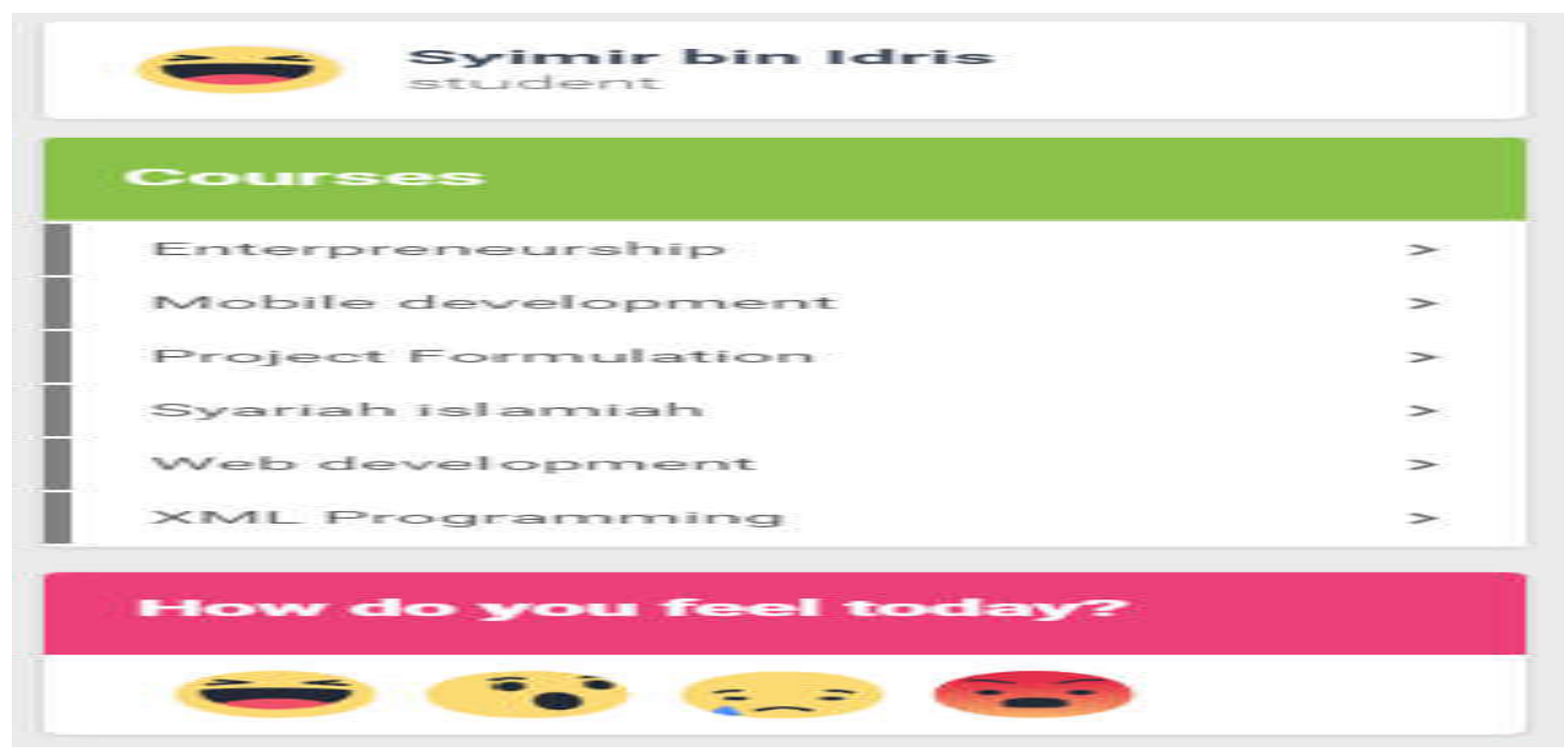

Fig.4. Emotion feedback section screenshot

Fig. 4 allows student to express their emotion for today and will change the student profile image with the chose emotion.

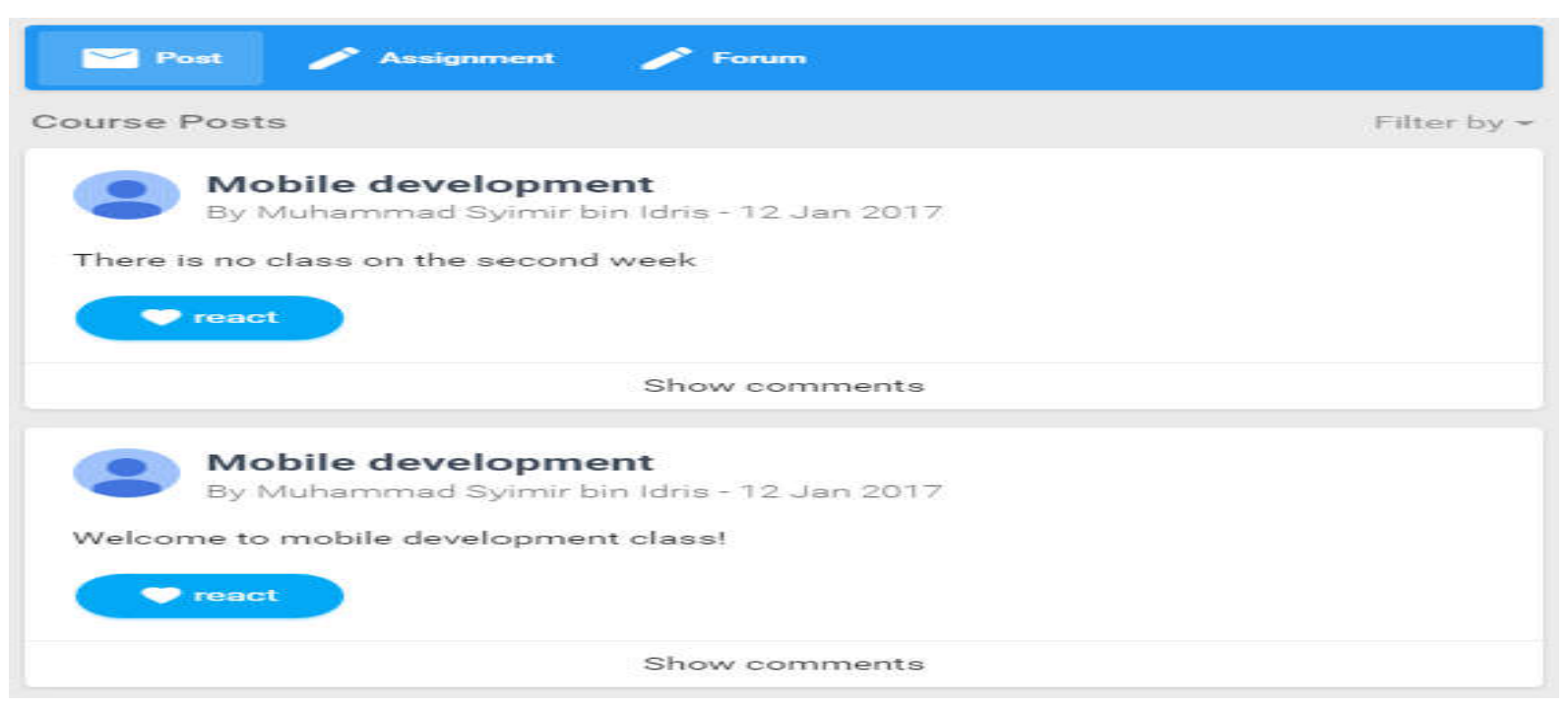

Fig.5. Post list section screenshot

Fig. 5 and Fig. 6 show the content at the center of the main page which will display course module post, assignment or forum for all courses. 


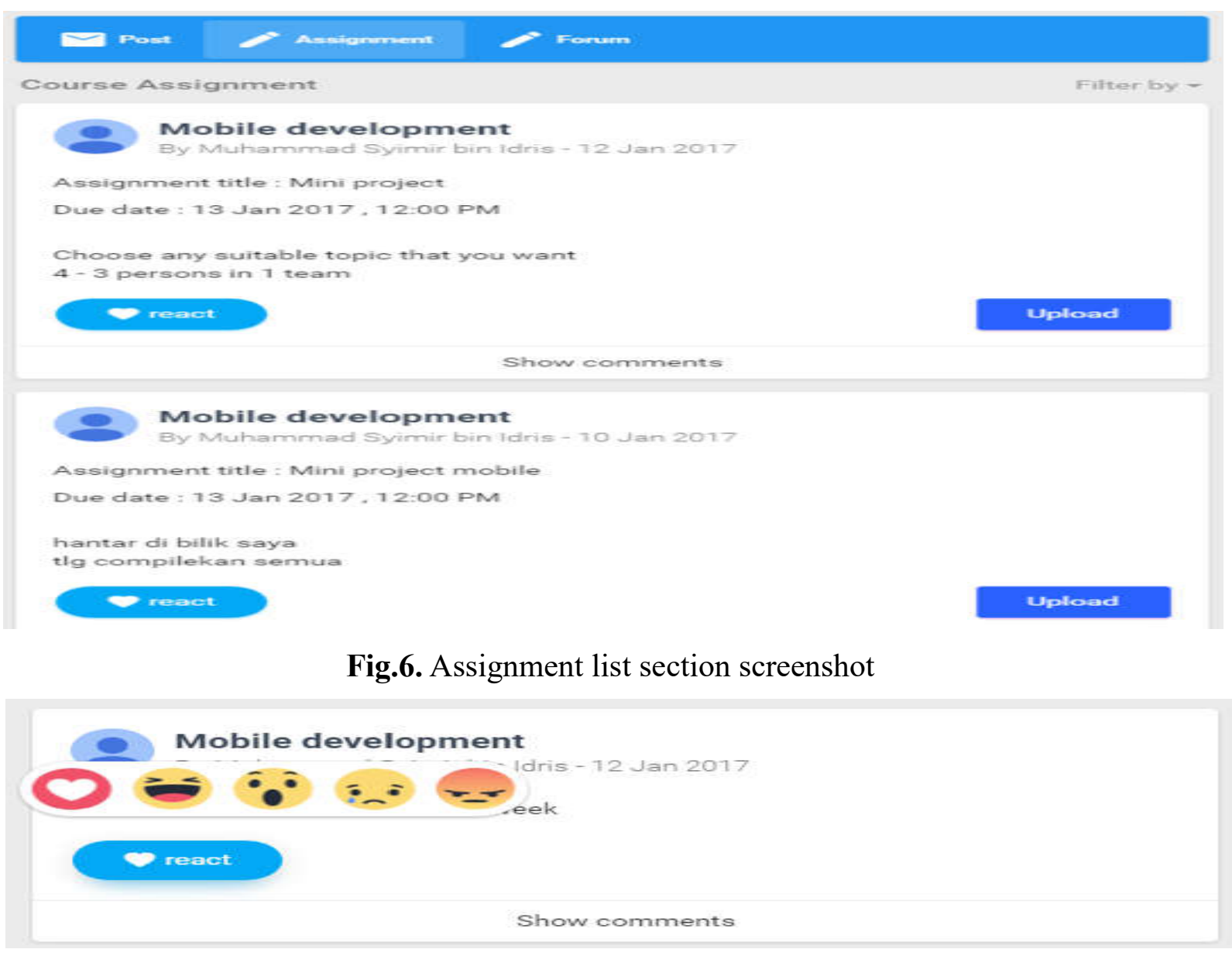

Fig.7. React button hover screenshot

Student can interact with the entire module by give emotional feedback by hovering the react button and click the intended emotion as shown in Fig. 7.

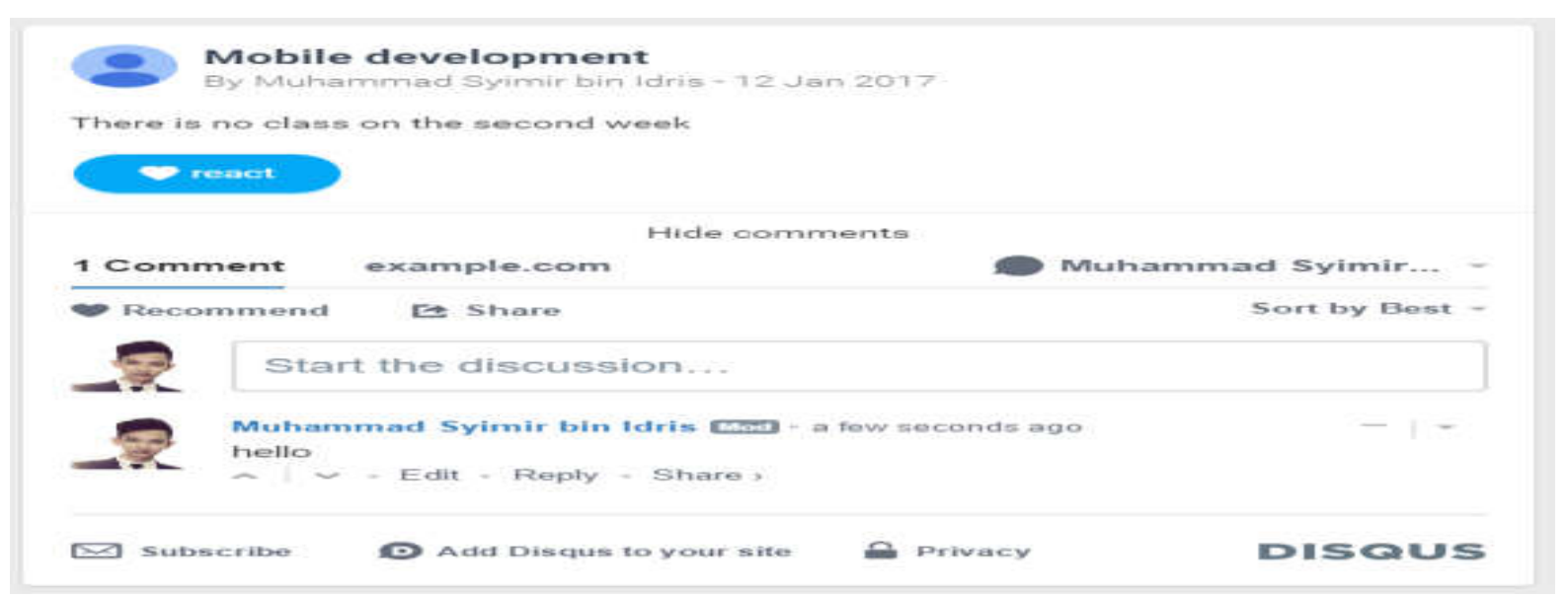

Fig.8. Comment section screenshot

Student can also give comment to the module by clicking the comment link. It will open comment section for the particular module. All the comments sent will be analyzed using third party API Indico to detect their emotion based on text they send (refer Fig. 8). 


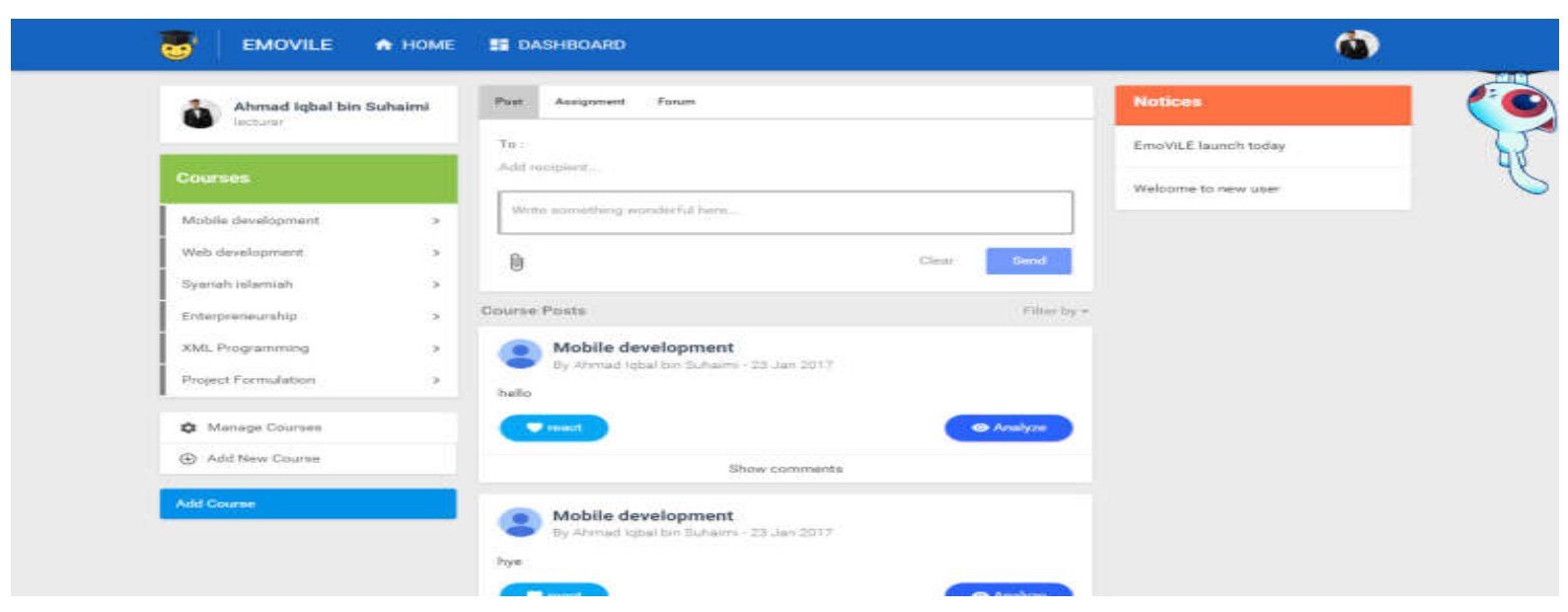

Fig.9. Lecturer main page screenshot

Fig. 9 shows the page whereby after successful login as the lecturer, the lecturer will be redirected to lecturer home page.

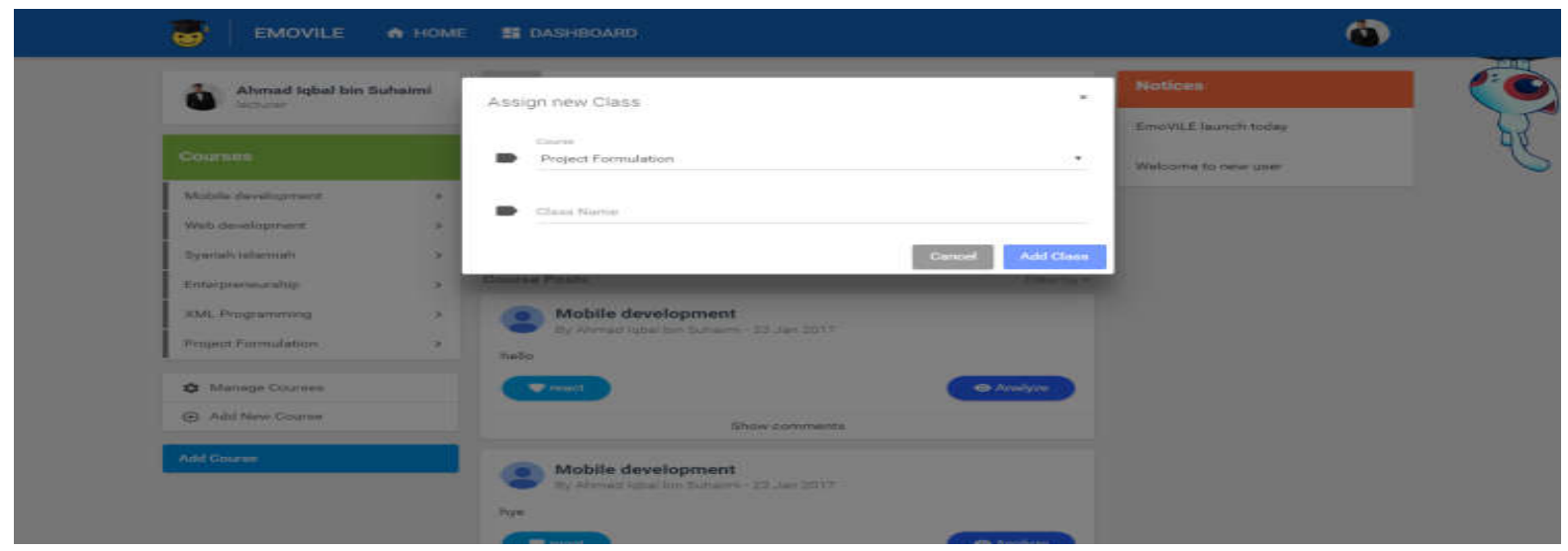

Fig.10. Lecturer main page screenshot

Fig. 10 shows the page whereby almost all elements are identical to student home page. The different is the change of emotional feedback for today section with other section, which is action button to add new class and manage class. The add new class button will open pop up window to create new class. 


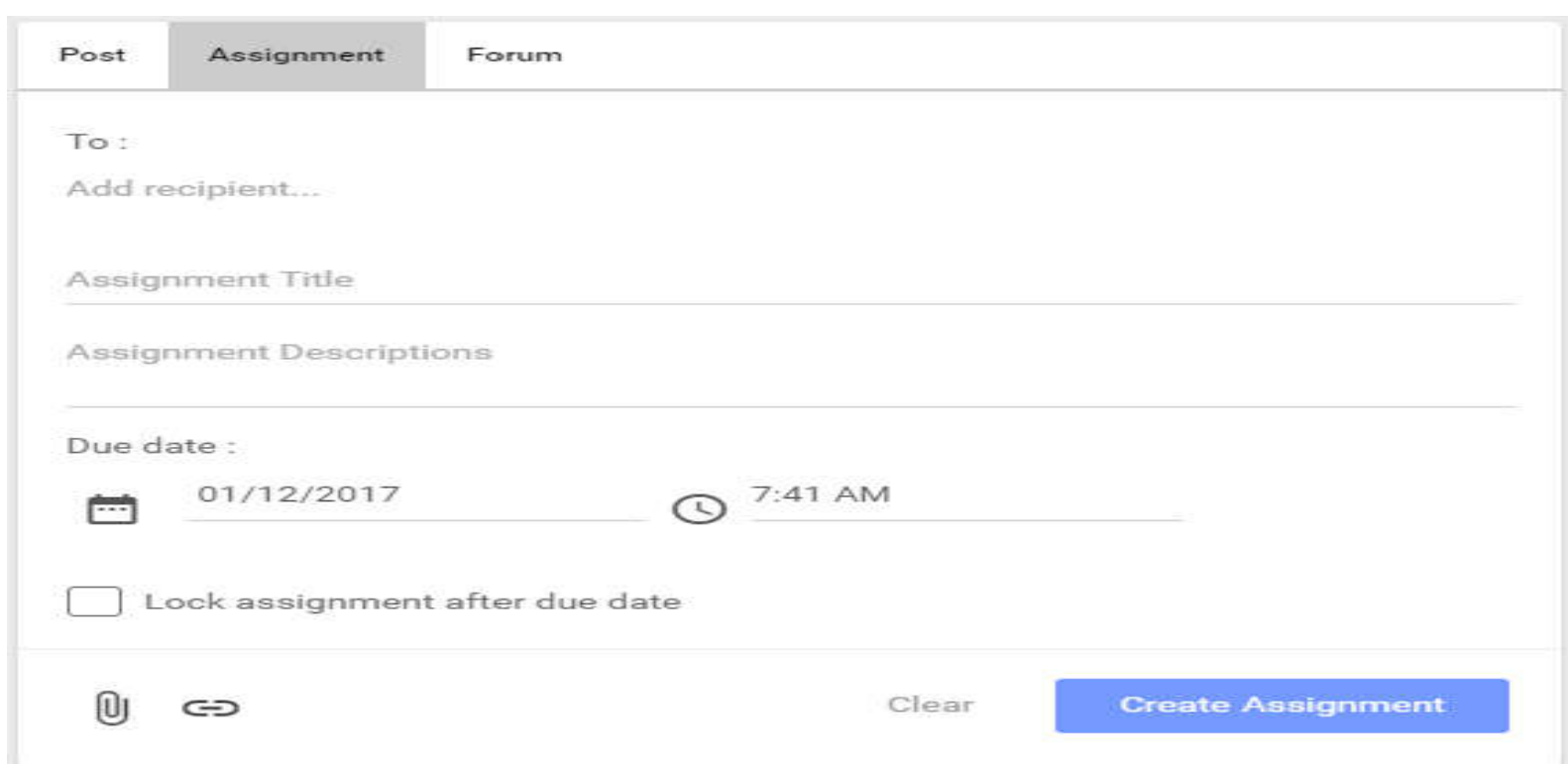

Fig.11. Create post section screenshot

The new class will then available for the lecturer to assign new student. Other different is the post section to send or create post, assignment or forum. This section will change their three functions above when user change the tab that available at the top (refer Fig. 11).

\begin{tabular}{l} 
Post Assignment Forum \\
To: \\
Add recipient... \\
Forum Title \\
Forum Descriptions \\
(i) $\leftrightarrow$ \\
\hline
\end{tabular}

Fig.12. Create forum section screenshot

Fig. 12 shows the post, assignment or forum that has been created which then can be viewed and interacts by the student under the class or course. Lecturer can change the receiver at the receiver input and can add multiple receivers at once. 


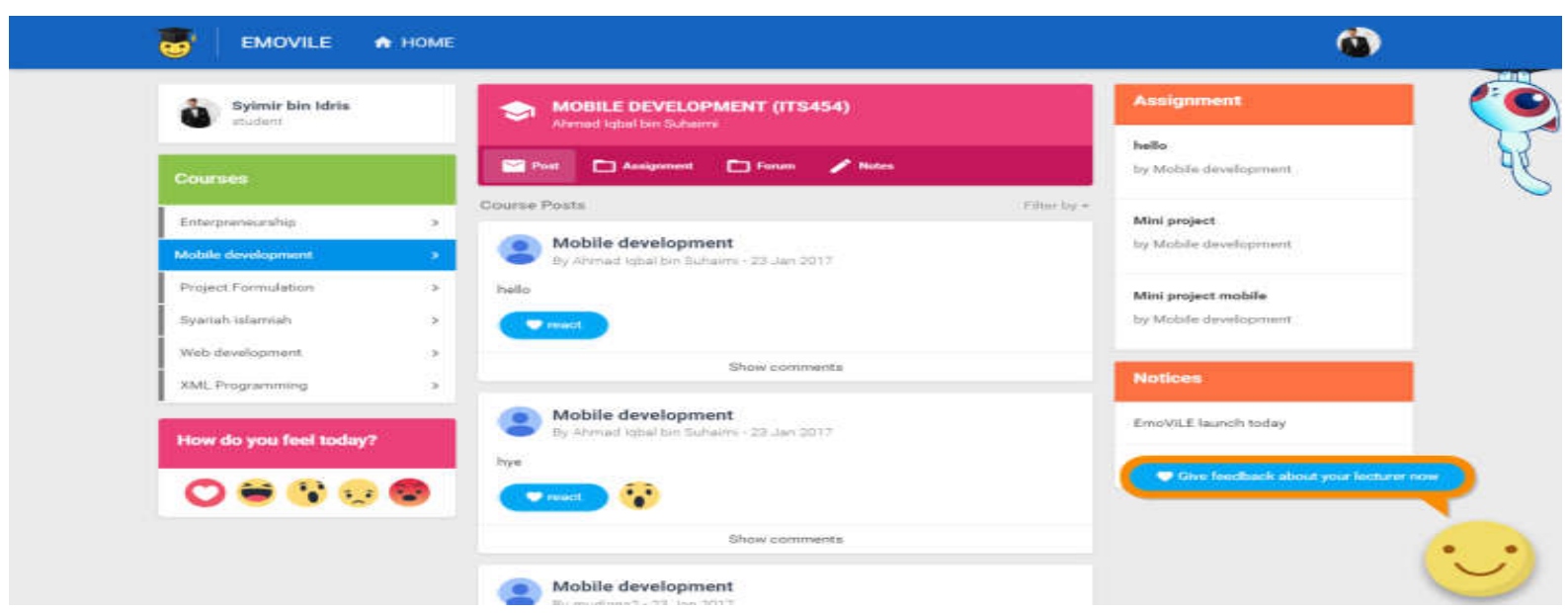

Fig.13. Student course page screenshot

Student can access this page by clicking course list navigation at the left side of the student main page. This page is identical to student home page, but with different content at the center of the page and minor different at the left side course navigation list (refer o Fig. 13).

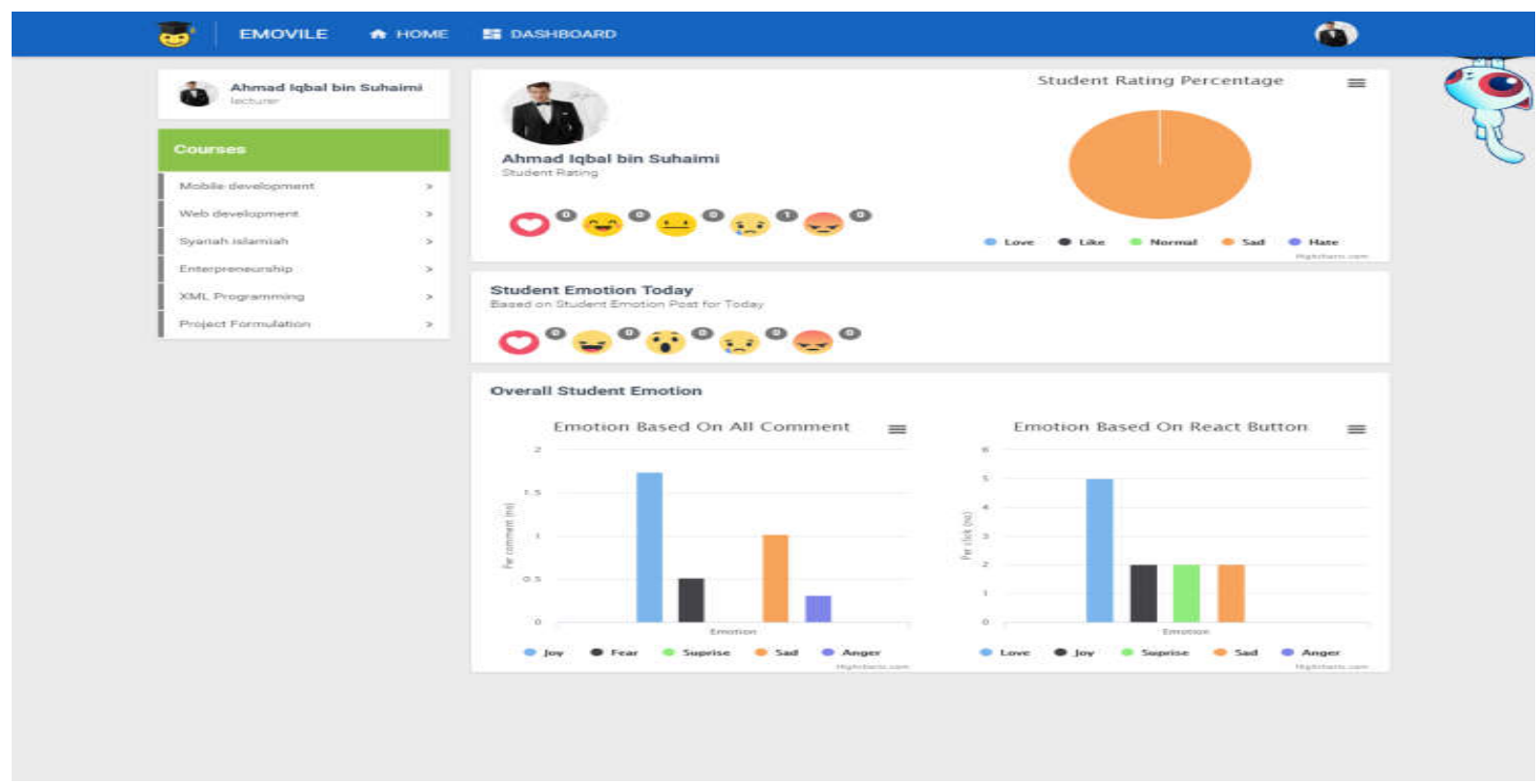

Fig.14. Dashboard page screenshot

Fig. 14 shows the dashboard of the EmoViLE that will display the statistic for the student emotion for each type of feedback. This page will show the emotion statistic for all the feedback available on the system. The first section will show the emotion statistic for lecturer rating. The second section will show the student emotion for the current day that the students choose to show. The third section will show the overall emotion statistic for all courses based on comment and "React" button. It will change to show only statistic for certain course if the lecturer click a course on the left side bar navigation. 


\subsection{Testing Methods}

User testing has been conducted on the focus group of the system. Two methods applied are user interview and system feedback using third party software that will implement in the system. Interview has been conducted same as the data collection procedures but using the new system that has been developed. The question focused on how the new system defer from the current system used in term of usability and functions. Next, Usabilla website live user feedback software has been used to conduct the testing to collect the user feedback of the individual element of the website such as navigation and each module section. Step-by-step process of the feedback has been taught to the user before it is being conducted. This is needed to decrease unreliable data from the user. The software let the user to give feedback on each elements of the system using their emotion. These methods will let the user emotion to be measured. In conclusion, the testing is conducted to find any flaws to be fixed to make sure the user are satisfied with the overall system.

\section{RESULTS AND DISCUSSION}

The data gathering procedures has result in several design elements. First, most of the students agree that the use on light color in the background and blue color in the navigation is most suitable. Second, the result in logo positioning are almost equally agreed to be at the left and center but the overall result more towards at the left side of the navigation. Third, the navigation should be more simple and straight forward. Fourth, login page should have the option to stay login on the website (cookies), useful when the user want to enter the website directly without login. The students also agree with the use of icons to represent some function of the system such as navigation or button to make it easier to scan with eye. Based on the interview, occasionally student also use a mobile browser to access the website which make most of them agreed for the website to use responsive design to support different screen size and device. Additional functions such as comment and emotion feedback feature also need to be added to support their requirements. This features also can be used by lecturer to monitors their students' emotion and feedback to improve the learning process. 


\section{CONCLUSION}

This project applies the proposed method to obtain optimal emotional design elements, which can closely conform to users' emotional needs on virtual learning environment (VLE). Furthermore, this method can be applied to other websites, not only on the VLE website. On the basis of knowing the importance of users and collecting users' true needs of requirements, user opinion and emotional feedback could be valuable. In this project, different data collection procedures have been conducted to collect the user requirements. Different types of user have been interviewed which are the lecturers and students. This can help to obtain reasonable data suitable for different stages of the development and to create emotional design elements for the VLE. In the stage of testing the design elements, Usabilla live user feedback has been used which enable user to give feedback based on their emotion they chose. By conducting the data collection procedures, it is obvious that the student prefer the light background and blue navigation bar at the top. Navigation also is the main aspect to be concerned which should be easy to learn and access. It is also has been proved that the availability of global and local navigation are crucial for the website design elements. The students also agree with the use of icon to represent some function of the system such as navigation or button. Furthermore, the students also prefer the website layout to be responsive to support different screen size and devices such as smartphone. Several functions also will be added such as comment and emotion feedback feature to meet the user's needs. Lastly, the students stated that the home page needs to be improved by putting appropriate contents and information.

\section{ACKNOWLEDGEMENTS}

Highly gratitude goes to the Universiti Teknologi MARA Selangor for funding this work by the internal grant called ARAS (File no 600-IRMI/DANA 5/3/ARAS (0178/2016)). Next, highly appreciation goes to the Faculty of Computer and Mathematical Sciences and Institute of Malay Thought and Leadership of Universiti Teknologi MARA for supporting this study. 


\section{REFERENCES}

[1] Pekrun R, Goetz T, Daniels L M, Stupnisky R H, Perry R P. Boredom in achievement settings: Exploring control-value antecedents and performance outcomes of a neglected emotion. Journal of Educational Psychology, 2010, 102(3):531-549

[2] Homrich N C, Frozza R, Schreiber J N. The use of emotions in student assessment in a virtual learning environment. In International Conference on Industrial Engineering and Operations Management, 2013, pp. 1-10

[3] Tagg A, Dickinson J. Tutor messaging and its effectiveness in encouraging student participation on computer conferences. International Journal of E-Learning and Distance Education, 2008, 10(2):33-55

[4] Nir-Gal O. Distance learning: The role of the teacher in a virtual learning environment. Ma'of u-Ma'aseh, 2002, 8:23-50

[5] Redzuan F, Lokman A M, Othman Z A. Kansei semantic space for emotion in online learning. In 3rd IEEE International Conference on User Science and Engineering, 2014, pp. $168-173$

[6] Lokman A M, Nuraihan E, Ibrahim M. The Kansei semantic space in children's clothing. In IEEE International Conference on Information Retrieval and Knowledge Management, 2010, pp. 85-90

[7] Noteborn G, Carbonell K B, Dailey-Hebert A, Gijselaers W. The role of emotions and task significance in virtual education. The Internet and Higher Education, 2012, 15(3):176-83

[8] Brandon J. E. The impact of a virtual social environment on online learning. Phd thesis, Tennessee: Union University, 2015

[9] Arguedas L M. Emotions awareness on virtual learning students. Master thesis, Barcelona: Open University of Catalonia, 2015

[10] Moore J L, Dickson-Deane C, Galyen K. e-Learning, online learning, and distance learning environments: Are they the same? The Internet and Higher Education, 2011, $14(2): 129-35$

[11] Acemoglu D, Laibson D, List J A. Equalizing superstars: The Internet and the democratization of education. The American Economic Review, 2014, 104(5):523-527 
[12] Van B M. Introduction: What is "virtual learning"? 2011, https://www.mackinac.org/14475

[13] Michael K. Virtual classroom: Reflections of online learning. Campus-Wide Information Systems, 2012, 29(3):156-165

[14] Chief Learning Officer-CLO Media. Virtual (learning) reality. 2013, http://www.clomedia.com/2013/04/03/virtual-learning-reality

[15] Chakraborty M, Nafukho F M. Strategies for virtual learning environments: Focusing on teaching presence and teaching immediacy. Internet Learning, 2015, 4(1):8-37

[16] Park B, Knörzer L, Plass J L, Brünken R. Emotional design and positive emotions in multimedia learning: An eyetracking study on the use of anthropomorphisms. Computers and Education, 2015, 86:30-42

[17] Hutson M. Beyond happiness: The upside of feeling down. 2015, https://www.psychologytoday.com/articles/201501/beyond-happiness-the-upside-feeling-dow

$\mathrm{n}$

[18] Hadiana A, Dauni P, Lokman A M. Kansei engineering implementation in designing user interface for web based academic information system. International Journal of Basic and Applied Science, 2016, 4(3):42-50

[19] Guo F, Liu W L, Cao Y, Liu F T, Li M L. Optimization design of a webpage based on Kansei engineering. Human Factors and Ergonomics in Manufacturing and Service Industries, 2016, 26(1):110-126

[20] Lee E, Kim G W, Kim W B. An authoring framework for emotion-aware user interface of mobile applications. Journal of Korea Multimedia Society, 2015, 18(3):376-386

[21] Heidig S, Müller J, Reichelt M. Emotional design in multimedia learning: Differentiation on relevant design features and their effects on emotions and learning. Computers in Human Behavior, 2015, 44:81-95.

\section{How to cite this article:}

Mokhsin M, Aziz AA, Shahuddin AZ, Lokman AM, Idris MS. Web-based virtual learning environment (emovile) with emotive interface feature. J. Fundam. Appl. Sci., 2017, 9(4S), 430-448. 